\title{
BIOLOGICAL SYNTHESIS OF SILVER NANOPARTICLES USING THE TUBEROUS ROOT EXTRACT OF IPOMOEA BATATAS AND THEIR CHARACTERIZATIONS AND ANTIBACTERIAL ACTIVITY
}

\author{
NAVEEN CHANDRA JOSHI*, JUHI CHHABRA \\ Department of Chemistry, Uttaranchal University, Dehradun, Uttarakhand, India. Email: drnaveen06joshi@gmail.com
}

Received: 11 April 2019, Revised and Accepted: 10 May 2019

\begin{abstract}
Objectives: Tuberous root extract based synthesis of silver nanoparticles (AgNPs), characterizations using Fourier-transform infrared spectroscopy (FT-IR), UV-visible, powder X-ray diffraction (XRD), field emission scanning electron microscopy (FESEM), energy dispersive X-ray (EDX) techniques, and antibacterial activity of AgNPs against Staphylococcus aureus, Staphylococcus mutans, Proteus vulgaris, and Escherichia coli.
\end{abstract}

Methods: Root extract of Ipomoea batatas (sweet potato) was prepared by boiling of small cut pieces of root with double distilled water. Added root extract with silver nitrate solution and centrifuged and collect the pellets. After several washing and drying, AgNPs have been preserved for characterizations and antibacterial activity.

Results: The synthesized AgNPs were well characterized by FT-IR, UV-visible, XRD, FESEM, and EDX methods, and significant zones of inhibition observed around the loaded AgNPs on the agar plates. The zones of inhibition have been achieved 36, 40, 46, and 32 mm for E. coli, P. vulgaris, S. mutans, and S. aureus.

Conclusion: The characterisation methods such as UV-Visible, FTIR, Powder XRD, FESEM and EDX indicate an efficient formation of AgNPs using root extract of I. batatas. The biologically synthesized AgNPs are found good antibacterial agents.

Keywords: Biological synthesis, Silver nanoparticles, Characterization methods, Antibacterial activity.

(C) 2019 The Authors. Published by Innovare Academic Sciences Pvt Ltd. This is an open access article under the CC BY license (http://creativecommons. org/licenses/by/4. 0/) DOI: http://dx.doi.org/10.22159/ajpcr.2019.v12i6.33561

\section{INTRODUCTION}

Nanotechnology in chemical, biological, and pharmaceutical sciences is the practice of production, working, and applications of materials under nano ranges (1-100 nm). A biological or green synthetic approach used to synthesize nanoparticles has recently emerged a new field of research. The chemical methods used to synthesize different nanoparticles are suffered from the use of hazardous chemicals, low efficiency, high cost, and not environmentally friendly [1]. A green synthetic process has many advantages over the conventional methods such as very low cost, minimization of harmful chemicals, eco-friendly, no additional cost on instrumentations, and highly efficient. Metal nanoparticles such as gold $(\mathrm{Au})$, silver $(\mathrm{Ag})$, palladium (Pd), copper $(\mathrm{Cu})$, and platinum $(\mathrm{Pt})$ have been synthesized extensively due to their importance in pharmaceutical and other industries [2-4]. These metal nanoparticles exhibited very unique physical and chemical properties and are useful in electronics, photonics, catalysis, and biomedical fields [5-8]. Among these metal nanoparticles, AgNPs have recognized one of the important metal nanoparticles used in pharmaceutics, air filtration, water detoxification, agriculture, textiles, and oxidation reactions [7-10]. After synthesis of nanoparticles using any biomaterials, suitable characterization methods are required to explore the physicochemical properties of nanoparticles. The characterization methods such as Fourier-transform infrared spectroscopy (FT-IR), field emission scanning electron microscopy (FESEM), UV-visible, powder $\mathrm{X}$-ray diffraction (XRD), and energy dispersive X-ray (EDX) are generally used to analyze the silver nanoparticles (AgNPs). It is necessary to all health-care industries to characterize nanomaterials using the abovementioned techniques before applications [11-13]

The biological activities of AgNPs are based on the shape, size, morphology, composition of particles, dissolution rate, surface phenomena, and nature of reducing agents used in the synthetic methods [5,13-16]. In the purposed work, we have used the tuberous root extract of Ipomoea batatas (sweet potato) to synthesize AgNPs. The edible roots of plant were collected from the local vegetable market near Uttaranchal University, Dehradun (India). Sweet potato or I. batatas is a starchy, and root vegetable has a sweet taste; it belongs to the family Convolvulaceae. The bulky tubers contain starch, vitamins, and sugary substances, and a tuber is highly nutritive that is also used as raw materials for distilleries. Medicinally, I. batatas is used as an antiasthmatic, antitumor, antidiabetic, anti-inflammatory, aphrodisiac, and anti-convalescent agents $[17,18]$.

\section{METHODS}

All the chemicals used in experimental work were of analytical grade (AR) and the glassware washed with $10 \% \mathrm{HNO}_{3}$ and double distilled water and then dried in tray dryer. The necessary solutions or mixtures were prepared in double distilled water.

\section{Preparation of tuberous root extract}

A tuber of I. batatas was peeled and cut into small possible pieces and then dried for $2-3 \mathrm{~h}$ at room temperature, and then, the cut pieces of tuber washed with double distilled water for removing all water soluble impurities. Take $2 \mathrm{~g}$ of washed pieces of the plant with $100 \mathrm{ml}$ of double distilled water in $250 \mathrm{ml}$ Erlenmeyer flask. Boil the content for $25-30 \mathrm{~min}$ at $60^{\circ} \mathrm{C}$ under controlled conditions and cooled the content and filter it. The filtrate was used as an extract to synthesize AgNPs and preserved at $4^{\circ} \mathrm{C}[1]$.

\section{Synthesis of silver nanoparticles}

$100 \mathrm{ml}$ of $0.01 \mathrm{M}$ silver nitrate $\left(\mathrm{AgNO}_{3}\right)$ solution was prepared by dissolving an adequate amount of the salt in double distilled water. Now, added $10 \mathrm{ml}$ of extract in $100 \mathrm{ml}$ of $\mathrm{AgNO}_{3}$ solution with a continuous shake. The formation of nanoparticles was indicated by a color change from colorless to silvery brown. The solution was now centrifuged with a constant rpm 10,000 for $15 \mathrm{~min}$, and the nanoparticles settled dawn. The 
pellets of nanoparticles have been washed with double distilled water and again centrifuged. Finally, the synthesized nanoparticles were heated at $60^{\circ} \mathrm{C}-65^{\circ} \mathrm{C}$ for $1 \mathrm{~h}$ under controlled conditions at hot air oven and preserved in airtight bottles for characterizations and further studies [8,9].

\section{Characterizations}

The characterization techniques such as FT-IR, powder XRD, FESEM, UV-visible, and EDX have been used to analyze AgNPs $[2,9,11]$.

\section{Antibacterial activity}

The antimicrobial activity of AgNPs was tested using well-diffusion method. The plates containing Muller-Hinton agar were prepared by introducing $15 \mathrm{ml}$ of liquid media on sterile Petri dishes. The AgNPs have been loaded in the wells and then incubated for $24 \mathrm{~h}$ at $37^{\circ} \mathrm{C}$; a zone of inhibitions obtained and measured around the nanoparticles for Staphylococcus aureus, Streptococcus mutans, Proteus vulgaris, and Escherichia coli [19-21].

\section{RESULTS}

\section{Fourier-transform infrared spectroscopy (FT-IR)}

FT-IR is used to detect the presence of bonds on the substances. FT-IR is rapid, economical, and non-destructive technique with high sensitivity and precisions. An interference-based spectroscopy explains the type of functional groups on the materials [22]. Broad peaks are obtained at $3852,3744,3416,1627,1383,1016$, and $571 \mathrm{~cm}^{-1}$ (Fig. 1), respectively.

\section{Ultraviolet (UV)-visible}

UV-visible spectroscopy is also very low cost, rapid, and very simple method of characterization. It can be used in a qualitative as well as quantitative analysis of nanomaterials. It is associated with the excitation of electrons from lower to higher energy levels; light with the precise amount of energy can cause transitions from one energy level to another. The UV-visible spectra of AgNPs have been obtained in the range of $360-800 \mathrm{~nm}$ (Fig. 2).

\section{Field emission scanning electron microscope (FESEM)}

The FESEM technique is basically used to observe the morphological behavior of nanoparticles. In this technique, electrons are released from a source of field emission and accelerated in a high electrical field gradient, and at a high vacuum, these electrons are centered and deflected by electronic lenses, and the FESEM images of AgNPs are represented in Fig. 3.

\section{Energy dispersive X-ray (EDX)}

EDX analysis with FESEM is used to elemental composition of nanomaterials and also a non-destructive technique. The peaks of EDX spectra are related to the true composition of the sample being analyzed; EDX detectors measure the relative abundance of X-rays against energy. The EDX spectra of AgNPs are shown in Fig. 4 (peaks possibly omitted: $2.145,9.717$, and $11.460 \mathrm{keV}$ ).

\section{Powder X-ray diffraction (XRD)}

Powder XRD is diffraction based analytical method and related to the diffraction of X-rays from nanoparticles. A diffraction pattern is obtained from the curve, intensity against the angle of detector $(2 \theta)$, and generally known as diffractogram (Fig. 5); characteristic peaks obtained at $9 \theta, 38 \theta, 44 \theta, 64 \theta, 77 \theta$, and $82 \theta$.

\section{Antibacterial activity}

Nanomaterials have gained an important role in the research fields of nanomedicine, nanotoxicology, and nanobiotechnology. In nanoform, silver is very effective to inhibit different microorganisms such as bacteria and fungi. Zones of inhibition were found $42,36,32$, and $36 \mathrm{~mm}$ for $S$. mutans, P. vulgaris, S. aureus, and E. coli at initial dosage of AgNPs (2.5 mg/ml).

\section{DISCUSSION}

The broad FT-IR peaks obtained at 3852, 3744, 3416, 1627, 1383, 1016, and $571 \mathrm{~cm}^{-1}$ (Fig. 1) indicate the presence of-OH,-SH,-NH,-C=O,-C-O,-
$\mathrm{C}-\mathrm{N},-\mathrm{C}-\mathrm{S},-\mathrm{C}-\mathrm{C}-\mathrm{Ag}-\mathrm{O}, \mathrm{Ag}-\mathrm{N}$, and Ag-C bonds on the surface of biologically synthesized AgNPs. The formation of AgNPs using root extract of I. batatas is observed at $375 \mathrm{~nm}$ and $390 \mathrm{~nm}$ after only $10 \mathrm{~min}$. The FESEM images indicated that the AgNPs are roughly spherical in shape, agglomerated, and uniformly distributed. The characteristic XRD peaks obtained at $9 \theta, 38 \theta, 44 \theta, 64 \theta, 77 \theta$, and $82 \theta$. These peaks are corresponding to $111,200,220,311$, and 222 planes, respectively. The other unassigned peaks indicate that the crystallisation of bioorganic phase on the surface of AgNPs. The EDX spectra shows that the biological formation of AgNPs with other carbon and oxygen atoms (Table 1).

A review of literature [19-21,24,-26] reveals that the AgNPs are very effective antimicrobial agent as over other nanoparticles. AgNPs can enter easily into the cells of microorganisms and then show a potential inhibition mechanism inside the cells which cause distortions and destroys the cell membranes; finally, it causes death of the microbial cells. Different amount of AgNPs was loaded on the agar plates, and after incubation period $\left(24 \mathrm{~h}\right.$ at $\left.37^{\circ} \mathrm{C}\right)$, a significant zone of inhibitions has been obtained for E. coli, P. vulgaris, S. mutans, and S. aureus. The antibacterial activity of AgNPs increased with increase of its dosage for all bacterial species, and the dosage variation was done from $2.5 \mathrm{mg} / \mathrm{ml}$

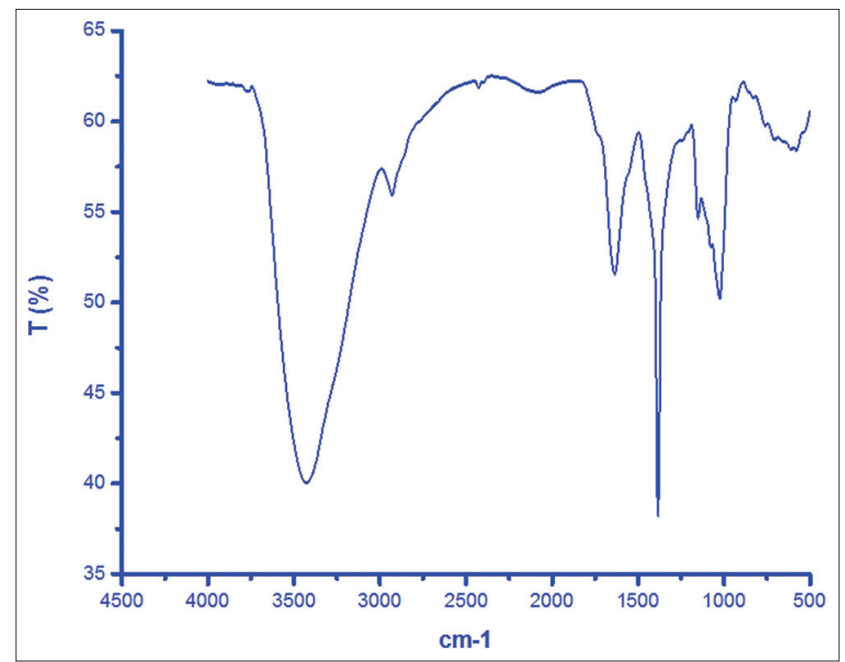

Fig. 1: Fourier-transform infrared spectroscopy spectra of silver nanoparticles synthesized using extract of Ipomoea batatas

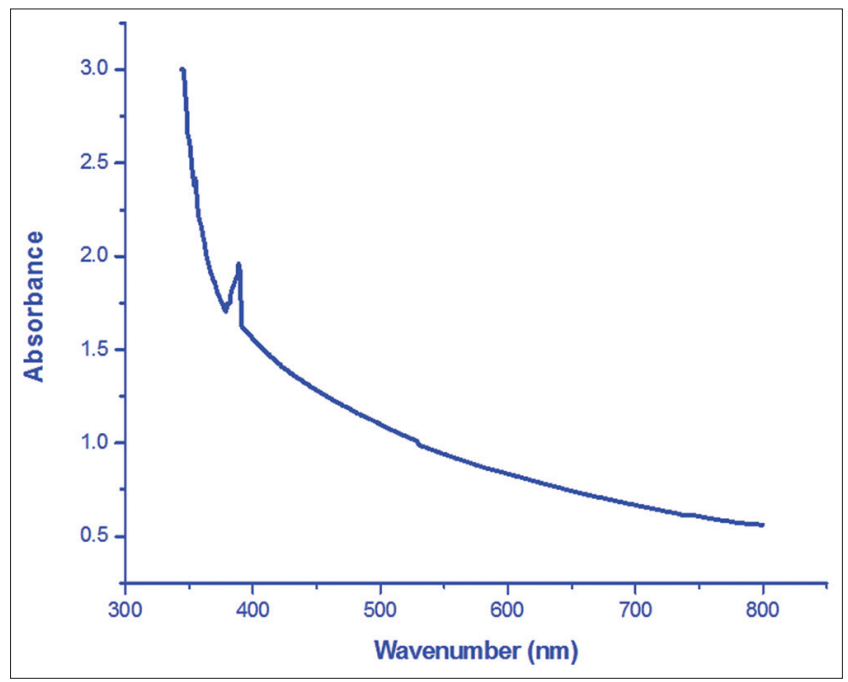

Fig. 2: Ultraviolet-visible spectra of silver nanoparticles synthesized using extract of Ipomoea batatas 

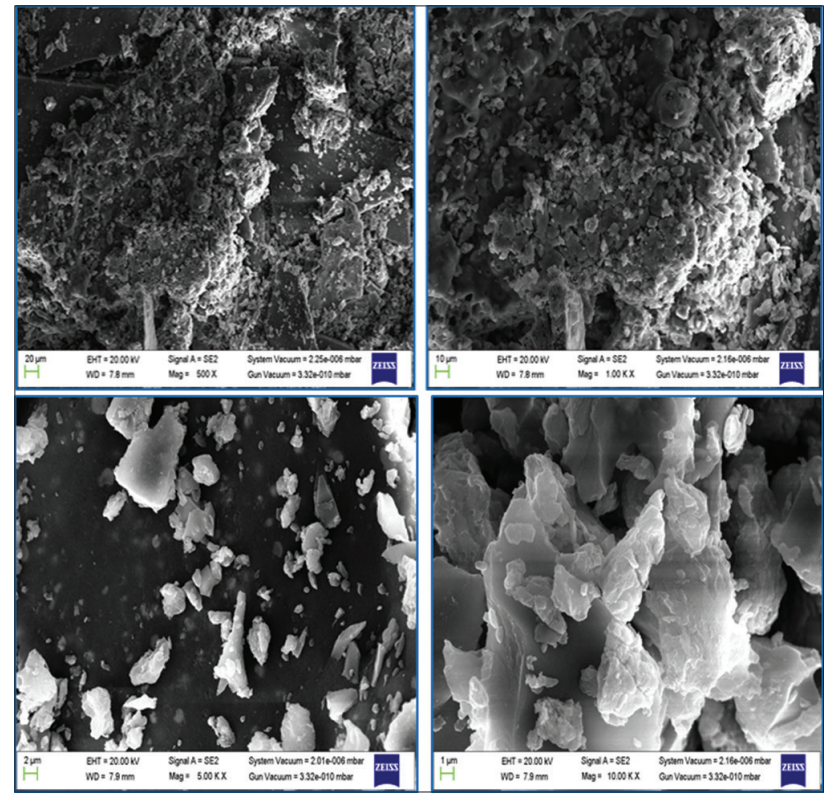

Fig. 3: Field emission scanning electron microscopy (FESEM) images of silver nanoparticles (AgNPs) synthesized using extract of Ipomoea batatas

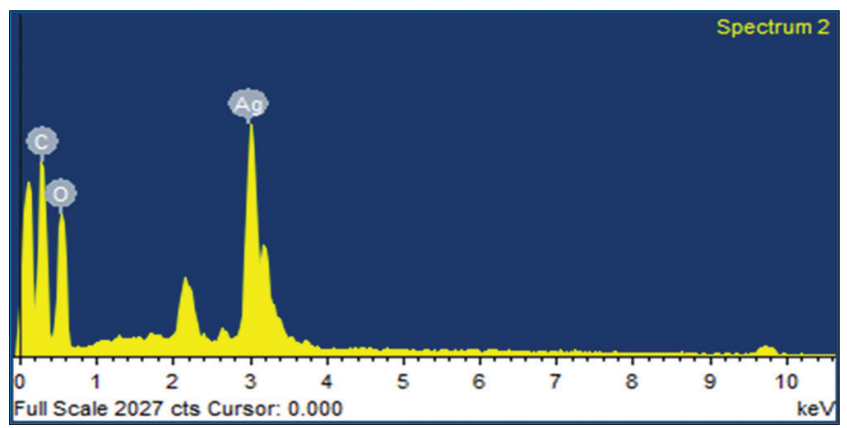

Fig. 4: Energy dispersive X-ray spectra of silver nanoparticles

to $10 \mathrm{mg} / \mathrm{l}$ (Fig. 6). At $10 \mathrm{mg} / \mathrm{ml}$ dosage of AgNPs, the zone of inhibitions has been achieved 36, 40, 46, and $32 \mathrm{~mm}$ for E. coli, P. vulgaris, S. mutans, and S. aureus.

\section{CONCLUSIONS}

The biologically synthesized AgNPs using the root extract of $I$. batatas as reducing reagent have been recognized as good antibacterial agents for S. aureus, S. mutans, P. vulgaris, and E. coli. The AgNPs were well characterized using different analytical methods such as UV-visible, FT-IR, XRD, FESEM, and EDX. The synthetic method was found highly efficient, low cost, eco-friendly, and specific.

\section{ACKNOWLEDGMENT}

We are very thankful to the Department of Chemistry, Uttaranchal University, Dehradun (India), for providing all facilities during the experimental works.

\section{CONFLICT OF INTEREST}

Authors declare that they have no conflict of interest.

\section{AUTHORS' CONTRIBUTIONS}

The ideas of this research work, characterizations, and antibacterial activity of AgNPs are mainly concerned with the corresponding author Dr. Naveen Chandra Joshi. The experimental work has performed by

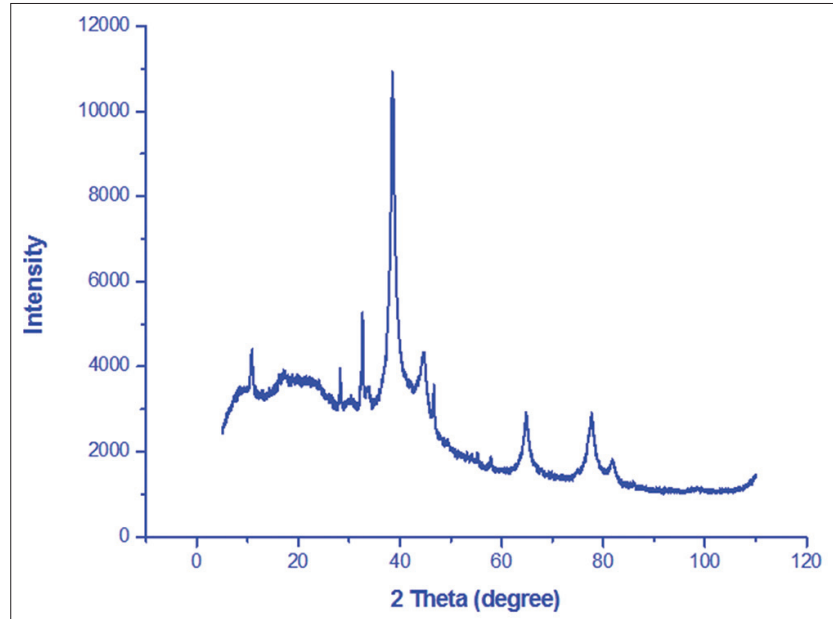

Fig. 5: Energy dispersive X-ray pattern of silver nanoparticles synthesized using extract of Ipomoea batatas

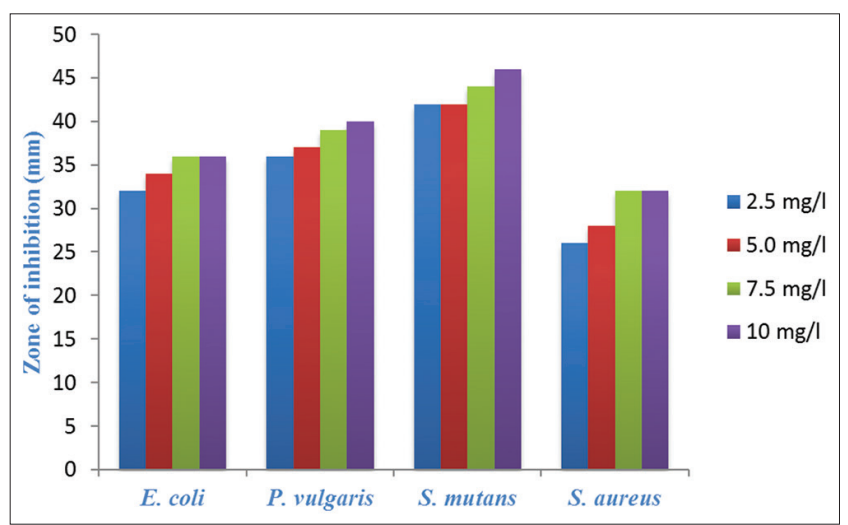

Fig. 6: Zone of inhibition for bacterial species at different amount of silver nanoparticles

Table 1: Energy dispersive X-ray composition

\begin{tabular}{lll}
\hline Element & Weight (\%) & Atomic (\%) \\
\hline C, K & 26.89 & 42.31 \\
O, K & 44.61 & 52.70 \\
Ag, L & 28.51 & 4.99 \\
Totals & 100.00 & \\
\hline
\end{tabular}

Ag: Silver, C: Carbon, K and L: Energy terms related to principle of EDX spectroscopy, 0: Oxygen

Mrs Juhi Chhabra in the advanced chemistry laboratory of Uttaranchal University, Dehradun (India), with the assessment of corresponding author.

\section{REFERENCES}

1. Patil SR, Sivaraj P, Rajiv R, Venckatesh R, Seenivasan R. Green synthesis of silver nanoparticle from leaf extract of Aegle marmelos and evaluation of its antibacterial activity. Intern J Pharm Pharma Sci 2015;7:169-73.

2. Raj LF, Jayalakshmy E. A biogenic approach for the synthesis and characterization of zinc oxide nanoparticles produced by Tinospora cordifolia. Intern J Pharm Pharm Sci 2015;8:384-6.

3. Menon S, Agarwal H, Kumar SR, Kumar SV. Green synthesis of silver nanoparticles using medicinal plant Acalypha indica leaf extracts and its application as an antioxidant and antimicrobial agent against foodborne pathogens. Intern J Appl Pharma 2017;9:42-50.

4. Anbarasu A, Karnan P, Deepa N, Usha R. Carica papaya mediated green synthesized silver nanoparticles. Intern J Current Pharma Res 2018;10:15-20.

5. Albanese A, Tang PS, Chan WC. The effect of nanoparticle size, shape, 
and surface chemistry on biological systems. Annu Rev Biomed Eng 2012;14:1-6.

6. Arvizo RR, Bhattacharyya S, Kudgus RA, Giri K, Bhattacharya R, Mukherjee P, et al. Intrinsic therapeutic applications of noble metal nanoparticles: Past, present and future. Chem Soc Rev 2012;41:2943-70.

7. Anandalakshmi K, Venugobal J, Ramasamy V. Characterization of silver nanoparticles by green synthesis method using Pedalium murex leaf extract and their antibacterial activity. Appl Nanosci 2017;6:399-408.

8. Behravan M, Hossein Panahi A, Naghizadeh A, Ziaee M, Mahdavi R, Mirzapour A, et al. Facile green synthesis of silver nanoparticles using Berberis vulgaris leaf and root aqueous extract and its antibacterial activity. Int J Biol Macromol 2019;124:148-54.

9. Sathishkumar M, Sneha K, Won SW, Cho CW, Kim S, Yun YS, et al. Cinnamon zeylanicum bark extract and powder mediated green synthesis of nano-crystalline silver particles and its bactericidal activity. Colloids Surf B Biointerfaces 2009;73:332-8.

10. Gan L, Zhang S, Zhang Y, He S, Tian Y. Biosynthesis, characterization and antimicrobial activity of silver nanoparticles by a halotolerant Bacillus endophyticus SCU-L. Prep Biochem Biotechnol 2018;5:1-7.

11. Lin PC, Lin S, Wang PC, Sridhar R. Techniques for physicochemical characterization of nanomaterials. Biotechnol Adv 2014;32:711-26.

12. Pleus R. Nanotechnologies-Guidance on Physicochemical Characterization of Engineered Nanoscale Materials for Toxicologic Assessment. Geneva, Switzerland: ISO; 2012.

13. Carlson C, Hussain SM, Schrand AM, Braydich-Stolle LK, Hess KL, Jones RL, et al. Unique cellular interaction of silver nanoparticles: Size-dependent generation of reactive oxygen species. J Phys Chem B 2008;112:13608-19.

14. Jo DH, Kim JH, Lee TG, Kim JH. Size, surface charge, and shape determine therapeutic effects of nanoparticles on brain and retinal diseases. Nanomedicine 2015;11:1603-11.

15. Staquicini FI, Ozawa MG, Moya CA, Driessen WH, Barbu EM, Nishimori $\mathrm{H}$, et al. Systemic combinatorial peptide selection yields a non-canonical iron-mimicry mechanism for targeting tumors in a mouse model of human glioblastoma. J Clin Invest 2011;121:161-73.

16. Duan X, Li Y. Physicochemical characteristics of nanoparticles affect circulation, biodistribution, cellular internalization, and trafficking.
Small 2013;9:1521-32

17. Park SY, Lee SY, Yang JW, Lee JS, Oh SD, Oh S, et al. Comparative analysis of phytochemicals and polar metabolites from colored sweet potato (Ipomoea batatas L.) tubers. Food Sci Biotechnol 2016;25:283-91

18. Majid M, Nasir B, Zahra SS, Khan MR, Mirza B, Haq I. Ipomoea batatas L. Lam. ameliorates acute and chronic inflammations by suppressing inflammatory mediators, a comprehensive exploration using in vitro and in vivo models. BMC Complement Altern Med 2018;18:216.

19. Wypij M, Czarnecka J, Świecimska M, Dahm H, Rai M, Golinska P, et al. Synthesis, characterization and evaluation of antimicrobial and cytotoxic activities of biogenic silver nanoparticles synthesized from Streptomyces xinghaiensis OF1 strain. World J Microbiol Biotechnol 2018;34:23.

20. Siddiqi KS, Husen A, Rao RAK. A review on biosynthesis of silver nanoparticles and their biocidal properties. J Nanobiotechnology 2018;16:14-42.

21. Fatimah I. Green synthesis of silver nanoparticles using extract of Parkia speciosa Hassk pods assisted by microwave irradiation. J Adv Res 2016;7:961-9.

22. Joshi NC, Singh A, Rajput H. Utilization of waste leaves biomass of Myrica esculenta for the removal of $\mathrm{Pb}$ (II), $\mathrm{Cd}(\mathrm{II})$ and $\mathrm{Zn}$ (II) ions from waste waters. Orient J Chem 2018;34:2548-53.

23. Chen S, Kimura K. Synthesis of thiolate-stabilized platinum nanoparticles in protolytic solvents as isolable colloids, J Phys Chem B 2001;105:5397-403

24. Pirtarighat S, Ghannadnia M, Baghshahi S. Green synthesis of silver nanoparticles using the plant extract of Salvia spinosa grown in vitro and their antibacterial activity assessment. J Nanostruct Chem 2019;9:1-9.

25. Elamawi RM,Al-Harbi RE, HendiAA. Biosynthesis and characterization of silver nanoparticles using Trichoderma longibrachiatum and their effect on phytopathogenic fungi. Egypt J Biol Pest Control 2018;28:28-39.

26. Young KJ, Byung HK, Geunhwa J. Antifungal activity of silver ions and nanoparticles on phytopathogenic fungi. Plant Dis 2009;93:1037-43. 